\title{
Dynamic monitoring of antimicrobial resistance using magnesium zinc oxide nanostructure-modified quartz crystal microbalance
}

\author{
Pavel Ivanoff Reyes*, Keyang Yang ${ }^{+}$, Andrew Zheng ${ }^{+}$, Rui Li, Guangyuan Li, and Yicheng Lu \\ Microelectronics Research Lab and Dept. of Electrical and Computer Engineering, Rutgers University \\ Chi Kwan Tsang, and Steven X.F. Zheng \\ Cancer Institute of New Jersey, Rutgers University
}

\begin{abstract}
Antimicrobial resistance (AMR) is becoming a major global-health concern prompting an urgent need for highly-sensitive and rapid diagnostic technology. Traditional assays available for monitoring bacterial cultures are time-consuming and labor-intensive. We present a magnesium zinc oxide (MZO) nanostructure-modified quartz crystal microbalance ( $\left.\mathrm{MZO}_{\text {nano }} \mathrm{QCM}\right)$ biosensor to dynamically monitor antimicrobial effects on E. coli and S. cerevisiae. MZO nanostructures were grown on the top electrode of a standard QCM using metal-organic chemical-vapor deposition (MOCVD). The MZO nanostructures are chosen for their multifunctionality, biocompatibility, and giant effective sensing surface. The MZO surfacewettability and morphology are controlled, offering high-sensitivity to various biological/biochemical species. MZO-nanotructures showed over 4-times greater cell viability over $\mathrm{ZnO}$ due to $\mathrm{MZO}$ releasing 4-times lower $\mathrm{Zn}^{2+}$ density in the cell medium than $\mathrm{ZnO}$. The $\mathrm{MZO}_{\text {nano-}}-\mathrm{QCM}$ was applied to detect the effects of ampicillin and tetracycline on sensitive and resistant strains of E.coli, as well as effects of amphotericin-B and miconazole on S. cerevisiae through the device's time-dependent frequency shift and motional resistance. The $\mathrm{MZO}_{\text {nano- }}$ QCM showed 4-times more sensitivity over $\mathrm{ZnO}_{\text {nano- }} \mathrm{QCM}$ and over 10-times better than regular
\end{abstract}


QCM. For comparison, the optical density at $600 \mathrm{~nm}\left(\mathrm{OD}_{600}\right)$ method and the cell viability assay were employed as standard references to verify the detection results from $\mathrm{MZO}_{\text {nano- }} \mathrm{QCM}$. In the case of $S$. cerevisiae, the $\mathrm{OD}_{600}$ method failed to distinguish between cytotoxic and cytostatic drug effects whereas the $\mathrm{MZO}_{\text {nano-}}-\mathrm{QCM}$ was able to accurately detect the drug effects. The

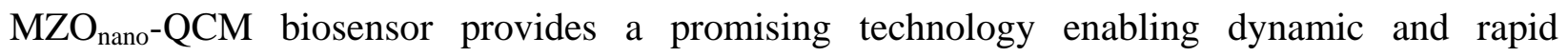
diagnostics for antimicrobial drug development and AMR detection.

*Email address: pavelrey@ rci.rutgers.edu

${ }^{+}$Equal contributions 


\section{Introduction}

Antimicrobial drugs have greatly reduced infection-related illness and death, however, the extended use of antibiotics causes microorganisms to become adapted to these drugs through genetic alterations, giving rise to antimicrobial resistance (AMR) (Odonkor, 2015). AMR threatens to become the next pandemic (World Health Organization 2014) and is becoming a major global-health concern according to the US Center for Disease Control (CDC). Successful treatment of antimicrobial resistance critically relies upon availability of new drugs. Therefore, developing new technologies to dynamically and rapidly detect the emergence of AMR will drastically improve the timeliness and choice of treatment methods (Livermore et al., 2011). The currently available conventional methods employed in screening antimicrobial susceptibility and resistance include the viability counting on agar, determination of minimum inhibitory concentration (MIC) from dilution protocols, the disk diffusion (Jorgensen, 2015), and the optical density (OD) spectrophotometric technique (Domingues et al., 2001; Yourassowsky et al. 1985). However, these testing methods heavily rely on monitoring large amounts of live microbial cell cultures. The repetitive monitoring of the microbial culture is typically handled under manual observation and assessment for further culturing or assaying. These periodic observations can be time consuming (usually takes a few days to obtain conclusive results), subjective, and require a large amount of samples in order to monitor the kinetics of growth of microbial cultures. The surface plasmon resonance (SPR) spectroscopy and the surfaceenhanced Raman scattering (SERS) spectroscopy have been developed to achieve rapid detection of antimicrobial susceptibility and resistance. SPR has been employed in analyzing the binding mechanisms of bacterial growth and other cell lines (Syal et. al, 2016, Giebel et al., 1999; Chabot et al., 2009). SPR detects of biochemical activity near the evanescent (surface plasmon) field and 
it provides information on binding in the molecular level, but usually requires invasive tagging molecules. SERS has been applied to rapidly detect antibiotic susceptibility and resistance (within a few hours) by spectroscopic monitoring of the chemical changes to the cell wall of the bacteria (Liu et al., 2009). These rapid spectroscopic methods require complicated and expensive optical measurement equipment. Due to the quick rise of AMR and the high burden it imposes on the technology of antimicrobial screening, there is a growing need for rapid, highly sensitive, compact, cost-effective, and dynamic sensor for AMR detection.

Zinc oxide $(\mathrm{ZnO})$ and its ternary compound magnesium zinc oxide (MZO) are wide bandgap semiconductors. With proper doping, $\mathrm{ZnO}$ and its nanostructures can be made into a multifunctional material that is particularly useful for sensing applications. For example, semiconducting $\mathrm{ZnO}$ was utilized to demonstrate a thin film transistor biosensor (bioTFT) (Reyes et al., 2011), and piezoelectric ZnO for acoustic wave sensors (Emanetoglu et al., 2003; Chen et al., 2007). $\mathrm{ZnO}$ can be grown with various morphologies (thin films, nanotips, nanorods, etc.) on various substrates, including metal electrode surfaces. Surface bio-functionalizations (Taratula et al., 2006), wettability control (Zhang et al., 2007), and high sensitivity of nanostructured $\mathrm{ZnO}$ with a large variety of biomolecules and biological species, such as oligonucleotides, enzymes, and antibodies (Zhang et al., 2007; Reyes et al., 2011) have been demonstrated. With a small percentage of $\mathrm{Mg}$ doping into $\mathrm{ZnO}$, the formed $\mathrm{MZO}$ essentially possesses all these properties of $\mathrm{ZnO}$. In addition, $\mathrm{MZO}$ improves its thermal stability (Ku et al., 2011) and enables to withstand a large $\mathrm{pH}$ range during device fabrication and bio-testing process (Chen et al., 2007; Brenner et al., 2014) in comparison with the pure $\mathrm{ZnO}$. The quartz crystal microbalance (QCM) is a popular bulk acoustic wave (BAW) device that has a high quality factor $(\mathrm{Q})$ with a frequency range of several $\mathrm{MHz}$ to tens of $\mathrm{MHz}$. It has the advantage of 
enabling dynamic measurements. The QCM has been used for detection of mass loading change. The QCM sensor has also been used in a number of biological applications (Braunhut, et al., 2005; Alessandrini et al., 2006; Lord et al., 2006) .

In this paper, we report the MZO nanostructure-modified quartz crystal microbalance $\left(\mathrm{MZO}_{\text {nano- }}-\mathrm{QCM}\right)$ biosensor. We applied the $\mathrm{MZO}_{\text {nano- }}-\mathrm{QCM}$ to demonstrate the rapid, highly sensitive, and dynamic monitoring of the effects of cytotoxic and cytostatic antimicrobial drugs on sensitive and resistant strains of E. coli and S. cerevisiae cultures. E. coli and S. cerevisiae were chosen as the example microbial species for our study since both species constitute among the major causes of microbial infections and food contaminations, as well as the most important standard model for the study of bacterial and fungal cell function and for developing antimicrobial drugs (Blount, 2015; Botstein and Fink, 2011). We demonstrate that the $\mathrm{MZO}_{\text {nano }}{ }^{-}$ QCM biosensor facilitates monitoring cultured bacterial cells automatically and continuously with fast minimal user intervention, requires a significantly small amount of samples to reliably detect antimicrobial sensitivity and AMR effects. This new technology is promising as the tool for rapid and real-time AMR detection and for applications in antimicrobial drug development for infectious diseases.

\section{Experimental Methods}

\subsection{Sensor Materials and Devices}

\subsubsection{MZO and ZnO Nanostructure Growth and Biosensor Device Fabrication}

For comparative studies, both $\mathrm{MZO}$ and $\mathrm{ZnO}$ nanostructured films were grown on glass substrates (used for control experiments) and directly on the top electrode of the standard QCM (International Crystal Manufacturers, Inc.) using metal organic chemical vapor deposition 
(MOCVD). Diethylzinc (DEZn), $\mathrm{MCp}_{2} \mathrm{Mg}$ (bis-(methyl-cyclopentadienyl) magnesium), and ultra-high purity (99.999\%) oxygen gas were used as the $\mathrm{Zn}$ metalorganic source, $\mathrm{Mg}$ metalorganic source, and oxidizer, respectively. The standard QCM's AT-cut quartz layer is sandwiched between two $100 \mathrm{~nm}$ gold electrodes. The sensing area of the top electrode is 0.2047 $\mathrm{cm}^{2}$. The schematic of the sensing device described in this section is shown in Fig. 1(a) and the SEM image of the $\mathrm{MZO}$ and $\mathrm{ZnO}$ nanostructure films are shown in Fig. 1(b)-(c) respectively. The fabrication reproducibility if the sensor mainly depends on the MOCVD deposition of the MZO nanostructured films, and the variability mainly affects the operational frequency of the resulting device. Our process showed good reproducibility as indicated by the standard deviation of $0.0171 \mathrm{MHz}$ of the average operating frequency of $9.9287 \mathrm{MHz}$ across six independent fabrication runs.

Nano-surface modification of sensor surfaces can achieve higher sensitivity as demonstrated for example by Della Ventura et al., 2015, and Zhang et al., 2007. The type of surface morphology and surface nanostructuring used in the sensor to achieve the desired extent of sensitivity depends on the size and type of the biological or biochemical species being immobilized or detected by the sensor. We have shown recently (Reyes et al., 2013) that various surface morphologies (smooth, rough and nanorods) of $\mathrm{ZnO}$ nanostructures would impact on its binding and viability with mammalian endothelial cells. We observed that device sensitivity favors the nanorod morphology since it provides very large effective sensing area, however, cells are more viable in smooth surfaces. To maintain both high sensitivity and high cell viability we used the optimized condition of rough nanostructured layer. In this current study on AMR effects, since the bacterial and fungal cells are of the same size as the cells studied in Reyes et al., 2013, we applied the similar principle of morphological control, however on the MZO 
materials to produce the optimized surface roughness of MZO through the control of the growth conditions to enhance the binding with E. coli and S. cerevisiae. The thickness of the nanostructured MZO film was controlled at 200-300 nm. The temperature was maintained at $400^{\circ} \mathrm{C} \sim 450^{\circ} \mathrm{C} . \mathrm{Mg}$ concentration was optimized to be at $4-5 \%$ through the control of the $\mathrm{Mg} / \mathrm{Zn}$ ratio of the precursors. By using ultraviolet (UV) illumination, the surface wettability of MZO and $\mathrm{ZnO}$ films was controlled to attain the hydrophilic state (Zhang et al., 2007) which dramatically enhances the sensitivity of the sensor and reduces the consumption of the liquid samples. The resulting $\mathrm{MZO}_{\text {nano-and }} \mathrm{ZnO}_{\text {nano-}}-\mathrm{QCM}$ devices possess the nanostructure- modified sensing surface with the optimized morphology and wettability, which leads to the higher sensitivity of the device.

\subsubsection{Sensor Measurements and Microbial Culture Setup}

The $\mathrm{MZO}_{\text {nano }}-\mathrm{QCM}, \mathrm{ZnO}_{\text {nano-}}-\mathrm{QCM}$ and a standard QCM (device without a $\mathrm{MZO}$ or $\mathrm{ZnO}$ film) were each used to continuously monitor the E. coli and S. cerevisiae. The operating frequencies of the standard $\mathrm{QCM}, \mathrm{ZnO}_{\text {nano }}-\mathrm{QCM}$, and $\mathrm{MZO}_{\text {nano }}-\mathrm{QCM}$ were measured to be 10 MHz, 9.9203 MHz, and 9.9181 MHz, respectively. All devices were sterilized and deployed inside a Teflon cell-growth well and seeded with the E. coli or S. cerevisiae cells, and placed inside a standard $\mathrm{CO}_{2}$ incubator under controlled temperatures $\left(37^{\circ} \mathrm{C}\right.$ for E. coli and $30^{\circ} \mathrm{C}$ for $S$. cerevisiae). The characterizations of the devices were conducted using an HP 8573D Network Analyzer (Agilent Technologies, Palo Alto, CA), which were connected via IEEE-488 general purpose interface bus (GPIB) to the universal serial bus (USB) of a microprocessor running a data acquisition program. The acoustic transmission $\left(S_{21}\right)$ spectrum of the device was automatically measured and digitally stored for a fixed monitoring interval during the microbial 
culture growth on the sensors inside the incubator. The output of the sensor devices was in the form of time-frequency set of signals. These signals were then analyzed by extracting the peak frequency shifts and admittance amplitude modulations experienced by the devices relative to their starting frequencies and amplitudes due to the mass change on the sensing surface.

\subsection{Biological Sample Preparation and Protocols}

\subsubsection{Chemical Reagents Drug Preparation and Plasmid}

The antimicrobial drugs used in this work are as follows: ampicillin and tetracycline served as the cytotoxic and cytostatic drugs respectively on E. coli, while amphotericin B and miconazole served as the cytotoxic and cytostatic drugs respectively for S. cerevisiae. Ampicillin was dissolved in water for a stock concentration of $50 \mathrm{mg} / \mathrm{ml}$. Tetracycline was dissolved in $70 \%$ ethanol for a stock concentration of $15 \mathrm{mg} / \mathrm{ml}$. Amphotericin B and miconazole were initially solubilized in dimethyl sulphoxide (DMSO) to a concentration of $10 \mathrm{mM}$. From this stock solution, working stock solutions were made with water for use in experiments. All stock reagents were kept in $-20^{\circ} \mathrm{C}$. The plasmid pQF used for preparing the drug resistant strain of $E$. coli was courtesy of Julia Vorholt (Addgene plasmid \# 48095).

\subsubsection{Bacterial Strains and Culture Medium}

The Escherichia coli strain DH5 $\alpha$ was used in this study. To generate ampicillin resistant strain, DH5 $\alpha$ was transformed with pRS425 plasmid which contains the ampicillin resistant marker as described in (Christianson et al., 1992). The ampicillin sensitive DH5a cells were grown in Luria-Bertani (LB) medium, whereas ampicillin resistant DH5 $\alpha$ cells were grown in LB medium in the presence of $50 \mu \mathrm{g} / \mathrm{ml}$ ampicillin. To construct tetracycline-resistant strain, DH5 $\alpha$ cells 
were transformed with the plasmid $\mathrm{pQF}$ which contains a tetracycline resistant marker. They were grown in LB medium containing $2 \mu \mathrm{g} / \mathrm{ml}$ tetracycline.

\subsubsection{Reference Bacterial Growth Curves}

The reference bacterial cell growth curves were determined by optical density (OD) measurement at $600 \mathrm{~nm}$ by spectrophotometer in $1.5 \mathrm{ml}$ disposable cuvettes (Einmal-Kuvetten). Bacterial cells were inoculated at an initial $\mathrm{OD}$ at $600 \mathrm{~nm}\left(\mathrm{OD}_{600}\right)$ in liquid $\mathrm{LB}$ medium and grown in incubation-shaker at $37{ }^{\circ} \mathrm{C}$. Drugs were added to the cell culture at early exponential phase. The cell culture with no drug treatment was used as a control. Aliquot of culture was withdrawn for $\mathrm{OD}_{600}$ measurement for each time point. Triplicate samples were used for each time point.

\subsubsection{Bacterial Viability Assay}

Bacterial cell viability was measured by counting the number of colony formation on agar plates as described in (Yourassowsky et al., 1985). Briefly, each sample was serially diluted from $10^{-2}$ to $10^{-4}$, spread on LB agar plates, and incubated in $37^{\circ} \mathrm{C}$ incubator. Colonies were counted after $24-48 \mathrm{~h}$ of incubation. The number of viable bacteria in the original sample was determined by counting the number of colony forming units (CFU) after adjusting the dilution factors. Triplicate samples were used for each experiment.

\subsubsection{Yeast Strain and Culture Medium and Viability Assay}

The budding yeast Saccharomyces cerevisiae strain FM391/BY4741 was used in this study. Yeast cultures were grown in yeast extracts-peptone supplemented with $2 \%$ dextrose (YPD) medium at $30^{\circ} \mathrm{C}$ incubator as described in (Li et al., 2006). Viability of yeast cells was determined by plating assay as described in (Tsang and Zheng, 2009). Briefly, overnight culture 
of yeast cells were inoculated in YPD medium. Amphotericin B ( $2 \mu \mathrm{M}$ final concentration), miconazole (30 $\mu \mathrm{M}$ final concentration) or drug vehicle control (DMSO) was added to the cells at $\mathrm{OD}_{600}$ of 0.4. After one hour of treatment, cells were counted with a hemocytometer, and 200 cells were spread on $2 \%$ agar YPD plates for 5 days at $30{ }^{\circ} \mathrm{C}$. Colonies were counted, and percent colony formation was calculated. Cell viability was compared with the corresponding untreated control. Each experiment was performed with triplicate samples.

\section{Results and Discussion}

\subsection{Calibration of Bacterial Culture Growth}

In order to monitor the $E$. coli growth using the $\mathrm{MZO}_{\text {nano }}, \mathrm{ZnO}_{\text {nano }}$ and regular QCM, an optimal initial cell seeding concentration must be determined. We extracted $E$. coli from the cultures under steady-state growth (overnight samples) and measured the sample's optical density value $\left(\mathrm{OD}_{600}\right)$ to serve as the reference. We then diluted the steady-state culture into three seeding concentrations so that their $\mathrm{OD}_{600}$ values were $0.01,0.05$, and 0.1 to serve as the initial cell seeding concentration. These cultures were placed in a shaking incubator in conditions outlined in Section 2.2. $1 \mathrm{~mL}$ of each of the cultures was extracted every 20 minutes for a total period of 3 hours to measure its $\mathrm{OD}_{600}$ using the spectrophotometer. The plots of $\mathrm{OD}_{600}$ versus time for various initial $\mathrm{OD}_{600}$ values represent the calibration growth curves for the E. coli culture as shown in Fig. 2(a). From these growth curves we determined that the cell concentration corresponding to the $\mathrm{OD}_{600}$ value of 0.1 is the optimal initial cell seeding concentration for all E. coli experiments as it shows the normal exponential growth phase (from 40 to160 minutes) and the reasonable onset time (at 160 minutes) of the stationary growth phase. We applied this initial seeding concentration to proportionately fill $2 \mathrm{~mL}$ of the cell culture into 
the $\mathrm{MZO}_{\text {nano }}-\mathrm{QCM}, \mathrm{ZnO}_{\text {nano }}-\mathrm{QCM}$, and standard QCM, respectively. The cultures were then allowed to grow on each of the devices for 180 minutes. Acoustic impedance spectra were taken automatically at 5-minute time intervals using the analyzer. The frequency shift $(\Delta f)$ of the spectra relative to the frequency of the spectrum at $t=0$ were measured and plotted as a function of time as shown in Fig. 2(b). $\Delta f$ of the device is directly proportional to the mass change $(\Delta m)$ that has accumulated on the sensing area of each device. The time evolution of $\Delta f$ of the each of the devices were compared with the time-dependent plots of OD values. The results showed good correspondence between the device output and the growth calibration curve corresponding to the $\mathrm{OD}_{600}=0.1$ initial cell seeding concentration. The $\Delta f(t)$ plots show an exponential growth phase from 30 to 170 minutes and the onset of the stationary growth phase starts at 170 minutes. Hence the initial seeding of $\mathrm{OD}_{600}=0.1$ was also applicable to our devices. The knowledge of the time points when the exponential growth phase is important because the drug treatment of the cell culture is most effective when the drug is introduced into the bacterial culture within the exponential growth phase. From the spectrophotometric calibration growth curves and $\Delta f(t)$ plots corresponding to the $0.1 \mathrm{OD}_{600}$ initial seeding concentration, the best time to introduce the drug into the bacterial culture is at 90 minutes from initial seeding, as determined in Fig. 2(b). Also using the growth curves of the $\mathrm{MZO}_{\text {nano-}}-\mathrm{QCM}$ and Sauerbrey's QCM calibration formulation (Sauerbrey, 1959) we determined the mass sensitivity of the $\mathrm{MZO}_{\text {nano-QCM sensor }}$ to be $0.13 \mu \mathrm{g} / \mathrm{kHz}$.

\subsection{Toxicity and Viability Evaluation of MZO and ZnO on E. Coli}

It has been reported that $\mathrm{ZnO}$ films and nanoparticles would release $\mathrm{Zn}^{2+}$ ions in aqueous solutions such as a cell culture medium, and that the $\mathrm{Zn}^{2+}$ ions were toxic to bacteria such as $E$. 
coli (Nel et al., 2009). This could pose a limitation to the sensitivity of the sensor which uses $\mathrm{ZnO}$ nanostructured films as the sensing surface. The release of $\mathrm{Zn}^{2+}$ ions from $\mathrm{ZnO}$ in acidic solutions (similar to the $E$. coli growth medium) originates from its wurtzite structure and the dangling bonds at the polar surface, and the $\mathrm{Zn}^{2+}$ ion formation proceeds as follows (Heiland and Kunstmann, 1969; Hupkes et al., 2012):

$$
\mathrm{ZnO}+2 \mathrm{H}^{+} \rightarrow \mathrm{Zn}^{2+}+\mathrm{OH}^{-}+\mathrm{H}^{+} \rightarrow \mathrm{Zn}^{2+}+\mathrm{H}_{2} \mathrm{O}
$$

where, the $\mathrm{Zn}-\mathrm{O}$ bond in $\mathrm{ZnO}$ nanostructures can be easily attacked by hydronium ions in the case of acidic solutions, and by hydroxide ions in the case of alkaline solutions. In our case where an acidic solution is used, the chemical equation (1) holds. This reaction generally proceeds increasingly forward as $\mathrm{pH}$ values get lower, and the stability of the $\mathrm{ZnO}$ film under this condition exists only in very narrow range of $\mathrm{pH}$ values (Pourbaix, 1974). However, in $\mathrm{MZO}, \mathrm{Mg}$ has a stronger bond to the metal oxide's surface compared to $\mathrm{Zn}$ to about two orders of magnitude, which effectively shields $\mathrm{Zn}$ from breaking away and forming $\mathrm{Zn}^{2+}$ ions, thus, providing chemical etching stability of MZO compared to ZnO (Brown et al., 1999; Brenner et al., 2014). Therefore, using MZO nanostructures as the sensor material would significantly reduce the toxicity issue due to $\mathrm{Zn}^{2+}$ ions migrating into the growth medium.

To determine the viability of growing $E$. coli on both $\mathrm{ZnO}$ and $\mathrm{MZO}$ films and confirm the cell growth improvement provided by $\mathrm{MZO}$ compared to $\mathrm{ZnO}$, we deposited the $\mathrm{ZnO}$ and MZO nanostructured films on glass substrates, then immersed them into a cell well filled with $2 \mathrm{~mL}$ of growth medium and seeded with $E$. coli at $0.1 \mathrm{OD}_{600}$ initial concentration. After 90 minutes, microscope images of the surfaces of $\mathrm{ZnO}$ and $\mathrm{MZO}$ films were taken and the number of $E$. coli cells growing within a $25 \mathrm{~mm}^{2}$ area was counted. It was found that both $\mathrm{ZnO}$ and $\mathrm{MZO}$ 
can viably sustain $E$. coli growth; however, there was over 4 times more $E$. coli cells growing on MZO than on $\mathrm{ZnO}$ as shown in the cell count results in Fig. 2(c). To verify that the improved viability of $E$. coli on MZO nanostructured films was due to the reduced concentration of $\mathrm{Zn}^{2+}$ ions released into the cell growth medium, we prepared two sets of vials each containing $2 \mathrm{~mL}$ of growth medium without the $E$. coli, and immersed a glass substrate coated with $\mathrm{ZnO}$ film in one and $\mathrm{MZO}$ film in the other. The $\mathrm{ZnO}$ and $\mathrm{MZO}$ samples were immersed in the bare medium for 90 minutes and then the substrates were removed from the vials. The growth mediums in each of the two vials were then analyzed for $\mathrm{Zn}^{2+}$ ions using an inductively coupled plasma mass spectrometer (ICP-MS). The ICP-MS measurement results (Fig. 2(d)) show that there is over 4

times more $\mathrm{Zn}^{2+}$ ion concentration in the medium that contained the $\mathrm{ZnO}$ coated glass substrates as compared to the medium that contained the MZO-coated glass substrates. The ICP-MS results closely correlated the increased cell growth on $\mathrm{MZO}$ and the decreased $\mathrm{Zn}^{2+}$ ion concentration found in the cell growth medium.

\subsection{Detection of Antimicrobial Effects and Antimicrobial Resistance on E. coli using MZO $_{\text {nano-QCM }}$}

Two main classes of antibiotics, ampicillin (cytotoxic antimicrobial) and tetracycline (cytostatic antimicrobial), were used to test the dynamic detection and sensitivity of $\mathrm{MZO}_{\text {nano- }}$ QCM, on the effect of these drugs on E. coli. Ampicillin is a penicillin $\beta$-lactam antibiotic that inhibits the enzyme transpeptidase, an enzyme essential for bacterial cell wall synthesis in binary fission, ultimately leading to cell lysis and apoptosis. On the other hand, tetracycline inhibits protein synthesis in bacteria by preventing the binding of aminoacyl-tRNA to ribosomal acceptor 
site; thus blocking mRNA translation causes the cell to stop growing and dividing. We applied these two types of drugs on a drug-sensitive strain and an antimicrobial resistant strain of E. coli.

For comparison, each of the $\mathrm{MZO}_{\text {nano }}-\mathrm{QCM}, \mathrm{ZnO}_{\text {nano }}-\mathrm{QCM}$, and regular $\mathrm{QCM}$ devices were deployed inside a Teflon cell growth well and filled with $2 \mathrm{~mL}$ of growth medium, placed inside the incubator and connected to the network analyzer. The medium was then seeded with drug-sensitive strains of $E$. coli corresponding to $0.1 \mathrm{OD}_{600}$ initial concentration. The acoustic wave spectrum of the device is then automatically taken every 5 minutes up to 150 minutes of total monitoring time. At 90 minutes after the initial seeding, the drug is carefully introduced into the cell culture. We used $256 \mu \mathrm{g} / \mathrm{mL}$ concentration for ampicillin and $8 \mu \mathrm{g} / \mathrm{mL}$ for tetracycline, respectively. The entire process was repeated for the antimicrobial resistant $E$. coli strains. Fig. 4(a-d) show the results of the detection of ampicillin and tetracycline effects on E.coli (sensitive and resistant strains) using regular $\mathrm{QCM}, \mathrm{ZnO}_{\text {nano }}-\mathrm{QCM}$ and $\mathrm{MZO}_{\text {nano }}-\mathrm{QCM}$, respectively. The regular QCM essentially had difficulty in cell growth detection due to low sensitivity of the device while both $\mathrm{ZnO}_{\text {nano }}-\mathrm{QCM}$ and $\mathrm{MZO}_{\text {nano }}-\mathrm{QCM}$ demonstrated accurate detection of bacterial count during active growth though frequency shifts $(\Delta f)$. In fact, both $\mathrm{MZO}_{\text {nano-}}-\mathrm{QCM}$ and $\mathrm{ZnO}_{\text {nano-}}-\mathrm{QCM}$ show significantly higher sensitivity (through larger $\Delta f$ values) than the regular $\mathrm{QCM}$, and that the $\mathrm{MZO}_{\text {nano }}-\mathrm{QCM}$ offers four-fold higher sensitivity than $\mathrm{ZnO}_{\text {nano-}}-\mathrm{QCM}$ which is consistent with our results regarding the four-fold reduction in $\mathrm{Zn}^{2+}$ ions released by MZO in growth medium (see Fig. 2(d)). For ampicillin-sensitive cells (Fig. 3 (a)), $\Delta f$ stopped increasing within 5 min after introducing the ampicillin; whereas $\Delta f$ value significantly declined within 10min following ampicillin treatment, indicating a steady decrease in the total mass of the cells on the sensor area due to cell detachment from the MZO (or $\mathrm{ZnO}$ ) nanostructures and eventual lysis into the medium. This trend in the sensor signal shows the 
characteristics of the cell-killing effects by ampicillin. In contrast, for the ampicillin-resistant cells $\Delta f$ continued increasing even after introducing the ampicillin (Fig. 3(b)) indicating the accumulation of the mass due to the continued cell growth after the drug treatment which characterizes the response of drug-resistant cells to the ampicillin treatment. Similar analysis of the $\Delta f(t)$ plots in Fig. 3(c-d) corresponding to the tetracycline treatment reveals the cytostatic effect exhibited by the tetracycline-sensitive $E$. coli cells through the observed flattened $\Delta f(t)$ plot upon antibiotic treatment (Fig. 3(c)) but not on tetracycline-resistant E. coli (Fig. 3(d)), where the $\Delta f(t)$ plot continued to increase even after the drug was introduced. These results were verified by the spectrophotometry $\left(\mathrm{OD}_{600}\right)$ which exhibited the same trends as $\mathrm{MZO}_{\text {nano }}-\mathrm{QCM}$ (Fig. 4(ad)). It should be noted that even if the $\mathrm{OD}_{600}$ spectrophotometric method showed the same trend as the $\mathrm{MZO}_{\text {nano }}-\mathrm{QCM}$, the $\mathrm{OD}_{600}$ method required at least $12 \mathrm{~mL}$ (compared to $2 \mathrm{~mL}$ for the $\mathrm{MZO}_{\text {nano }}-\mathrm{QCM}$ ) of cell culture samples for the total monitoring period; furthermore, the $\mathrm{OD}_{600}$ method required repetitive manual extraction of $1 \mathrm{~mL}$ of samples for each time interval within the entire monitoring period. To further verify the results of the $\mathrm{MZO}_{\text {nano }}-\mathrm{QCM}$ detection of the drug effects, we performed a bacterial viability assay outlined in Section 2.2.4. Fig. 5(a) shows the histogram of the viability assay for the effects of ampicillin on sensitive and resistant strains of E. coli. The viability assay results for ampicillin shows that there is significant reduction in viable cells from $4.8 \times 10^{4} \mathrm{CFU} / \mathrm{mL}$ to $0.9 \times 10^{4} \mathrm{CFU} / \mathrm{mL}$ for ampicillin treatment of the drug sensitive $E$. coli cells. On the other hand, there is small change in the viable cell count (from 6.1 x $10^{4} \mathrm{CFU} / \mathrm{mL}$ to $5.9 \times 10^{4} \mathrm{CFU} / \mathrm{mL}$ ) observed for the ampicillin treatment of the drug resistant E. coli cells. Fig. 5(b) shows the histogram of the viability assay exhibiting the effects of tetracycline on sensitive and resistant strains of E. coli. Similar analysis of the viability assay histogram for the tetracycline effects demonstrate the viable cell count reduction in sensitive 
strains and small change in viable cell count for the tetracycline resistant E. coli. As can be seen from the results of the $\mathrm{MZO}_{\text {nano- }} \mathrm{QCM}$ sensor, compared to the spectrophotometric method, it required only $2 \mathrm{~mL}$ of the bacterial culture for the entire monitoring period whereas the $\mathrm{OD}_{600}$ method required significantly more (at least $12 \mathrm{~mL}$ ). Also, once the $\mathrm{MZO}_{\text {nano }}-\mathrm{QCM}$ device has been initialized to run, it will not require any user intervention for the duration of its monitoring period whereas the $\mathrm{OD}_{600}$ requires $1 \mathrm{~mL}$ sample extraction every fixed time interval for the duration of the monitoring cycle. In the case of the viability assay, it takes a few days to accurately determine the drug effects on the bacterial colony whereas the $\mathrm{MZO}_{\text {nano- }} \mathrm{QCM}$ can detect the drug effects within an hour in real time.

\subsection{Motional Resistance Analysis of Antimicrobial Effects and Antimicrobial Resistance on E. coli using $\mathrm{MZO}_{\text {nano }}-\mathrm{QCM}$}

In addition to the time evolution of the frequency shift, another dynamic parameter, the motional resistance $\left(R_{\text {Load }}\right)$ is analyzed to extract information about the antimicrobial effects on E. coli growth. The time-dependent amplitude modulation of the admittance spectrum of the $\mathrm{MZO}_{\text {nano- }}-\mathrm{QCM}$ yields the $R_{\text {Load }}$ of the accumulated mass on the sensor surface (Wegener et al., 2000). $R_{\text {Load }}$ has a direct relation to the mechanical resistance and acoustic energy dissipation introduced by the accumulated mass of the $E$. coli cell on the $\mathrm{MZO}_{\text {nano }}-\mathrm{QCM}$, and is obtained directly from the admittance spectrum using the relation:

$$
R_{\text {Load }}=\frac{\pi}{4 K^{2} \omega_{0} C_{0}} \frac{\operatorname{Re}\left\{Z_{\text {mechL }}\right\}}{Z_{Q C M}}=\frac{\operatorname{Re}\left\{Y_{\text {Load }}\right\}}{\operatorname{Re}^{2}\left\{Y_{\text {Load }}\right\}+\operatorname{Im}^{2}\left\{Y_{\text {Load }}\right\}}
$$


where $K^{2}$ is the coupling coefficient of AT-cut quartz in the QCM, $Z_{\text {mech }}$ is the mechanical impedance due to the dynamic mass loading, $Z_{Q C M}$ is the impedance the $\mathrm{MZO}_{\text {nano- }}-\mathrm{QCM}$ at no load, and $Y_{\text {Load }}$ is the admittance spectrum of the sensor. We calculated the time-dependent motional resistance of the $E$. coli cells growing on the $\mathrm{MZO}_{\text {nano }}-\mathrm{QCM}$ for the ampicillin and tetracycline drug treatments using the admittance spectrum obtained from the dynamic monitoring of the cell growth. Fig. 5(c) summarizes the results. The case with no drug treatment (Fig. 5(c) square plots) show consistently increasing motional resistance from the start to finish of the cell growth monitoring cycle. This implies that as the cells divide and accumulate on the surface of the sensing area, the ensemble of cells form an increasingly rigid layer that dissipates the acoustic energy provided by the resonating quartz. On the other hand, in the case of ampicillin-treated cells (Fig. 5(c) circle plots) show that $R_{\text {Load }}$ is increasing from start of the monitoring period up to 90 minutes (the time when the ampicillin is introduced), and then starts to decrease rapidly after ampicillin has been added. The decrease in the motional resistance after 90 minutes indicates that the accumulated layer of E. coli cells started to respond to the ampicillin treatment and has become more elastic up to the point of detachment from the MZO nanostructure and eventual lysis into the medium. For the Tetracycline treatment case, the $R_{\text {Load }}(t)$ plot (Fig. 5(c) triangle plot) shows increasing motional resistance up to 90 minutes when tetracycline was introduced into the cell culture, after which the motional resistance stays flat up to the end of the monitoring cycle, which indicates the inhibitory effect of tetracycline to the $E$. coli growth.

\subsection{Detection of Antimicrobial Effects and Antimicrobial Resistance on S. cerevisae using MZO $_{\text {nano-QCM }}$}


We repeated the same procedure of growth calibration and drug effect monitoring of the E. coli cells to the fungal strain S. cerevisiae. Preparation of the medium and growth protocols for S. cerevisiae are outlined in Section 2.2.5. For the S. cerevisiae cell culture, we used amphotericin B as the cytotoxic drug and the miconazole as the cytostatic drug, respectively. Fig. 6(a) shows the results of the $\mathrm{OD}_{600}$ measurements for the S. cerevisiae cell growth with and without the antifungal drug treatment for both the amphotericin B and miconazole drugs. Fig. 6(b-d) show the $\mathrm{MZO}_{\text {nano }}-\mathrm{QCM}$ and $\mathrm{ZnO}_{\text {nano }}-\mathrm{QCM}$ responses to the $S$. cerevisiae cell growth with and without the antifungal drug treatment for both the amphotericin B and miconazole drugs. Note that both the $\mathrm{ZnO}_{\text {nano }}-\mathrm{QCM}$ and $\mathrm{MZO}_{\text {nano }}-\mathrm{QCM}$ devices accurately sensed the cytotoxic effects of amphotericin B and cell growth inhibition effects of miconazole. Again, the $\mathrm{MZO}_{\text {nano-}}-\mathrm{QCM}$ shows more than 4 times higher sensitivity over $\mathrm{ZnO}_{\text {nano- }}-\mathrm{QCM}$ and that both devices have a significantly higher sensitivity than the regular QCM. Fig 6(a) shows that the $\mathrm{OD}_{600}$ measurements cannot distinguish the cell-killing effects of amphotericin $\mathrm{B}$ and the cellinhibitory effects of miconazole on the $S$. cerevisiae cell cultures. This could be due to the fact that the $\mathrm{OD}_{600}$ technique is dependent on the optical absorption of the cells in suspension to indicate indirectly how many cells are in the sample. However, when $S$. cerevisiae cells die due to amphotericin-B treatment, the dead cells reduces in density but do not lyse. The dead cells remain suspended among the living cells, therefore, the optical absorption cannot tell the difference between the living and dead cells. On the other hand, the dead cells detach themselves from the $\mathrm{MZO}_{\text {nano- }}-\mathrm{QCM}$ sensing surface. The reduction in cell density results in the decrease in the frequency shift. This contributes to the accurate and dynamic monitoring of cytotoxic drug effect by the $\mathrm{ZnO}_{\text {nano }}-\mathrm{QCM}$. 


\subsection{Conclusion}

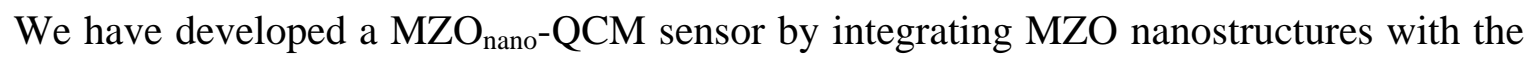
QCM. A small percentage amount of $\mathrm{Mg}$ doping into $\mathrm{ZnO}$ forms $\mathrm{MZO}$, which decreases the $\mathrm{Zn}^{2+}$ concentration in the cell medium by 4 times compared to the pure $\mathrm{ZnO}$, lowering the toxicity of the sensor with the cell culture. The sensing surface is further modified by MZO with the proper morphology and wettability to enhance the cell binding. The $\mathrm{MZO}_{\text {nano- }} \mathrm{QCM}$ sensor has demonstrated high sensitivity, enabling accurate and real-time monitoring and detection of cytostatic and cytotoxic antimicrobial effects on E. coli and S. cerevisiae, and detecting antimicrobial resistance. Bacterial growth measured by acoustic signals mainly the timedependent frequency shift and dynamic motional resistance showed highly accurate trends as verified by traditional methods of optical density spectrophotometry, as well as the cell viability assay. Moreover, it rapidly detects these drug effects within 10 minutes after drug treatment, which can inform whether the bacterial strain is responsive to antimicrobial treatment, or it has developed antimicrobial resistance. The sensor only required a small amount of samples for detection, (2mL for $\mathrm{MZO}_{\text {nano-}}-\mathrm{QCM}$ as compared to $12 \mathrm{~mL}$ for the $\mathrm{OD}_{600}$ method). With current traditional testing methods, bacterial and fungal samples must be cultured for an extended time period to measure drug treatment response. The micro-scale and dynamic monitoring capability of $\mathrm{MZO}_{\text {nano-}}-\mathrm{QCM}$ makes it possible for rapid detection of antimicrobial responses in small clinical samples. In this paper we dealt mainly with the qualitative aspects of the time-dependent parameters of the sensor reporting cell culture behavior in a collective manner. It is expected that this technology can be readily extended to quantitative analysis and applicability to other pathogenic microorganisms. The $\mathrm{MZO}_{\text {nano-}} \mathrm{QCM}$ shows the promising features and capability to 
meet the urgent needs to rapidly monitor treatment outcomes with high sensitivity, low cost, and compact size.

\section{Acknowledgement}

This work was supported in part by the National Science Foundation grant NSF-CBET 1264508. 


\section{Figures and Captions}
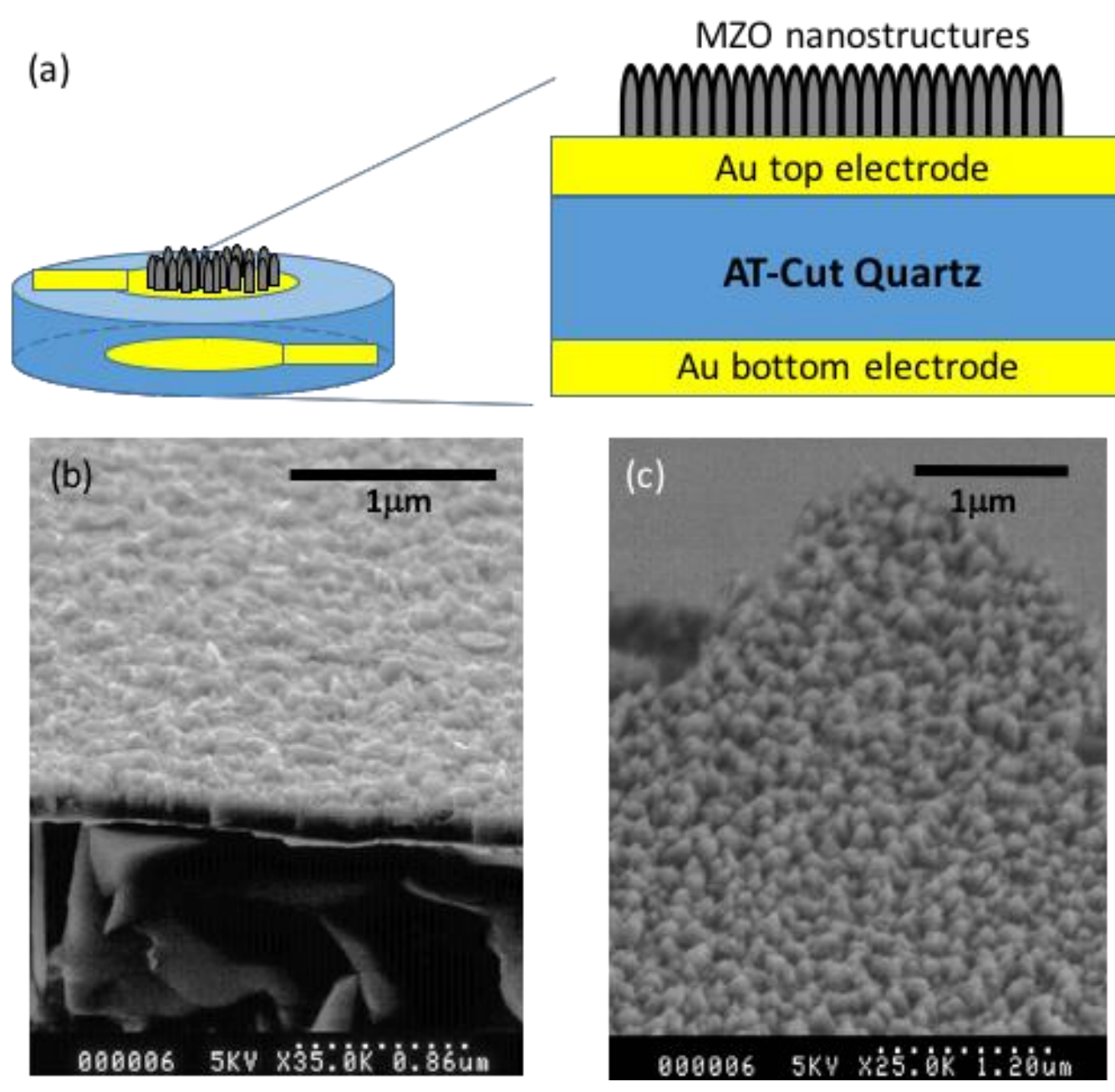

Fig. 1. (a) Schematic of the $\mathrm{MZO}_{\text {nano }}-\mathrm{QCM}$ biosensor, (b) FESEM image of the MOCVD-grown MZO nanostructure film and (c) FESEM image of a $\mathrm{ZnO}$ nanostructured film. Both $\mathrm{MZO}$ and $\mathrm{ZnO}$ films exhibit the rough surface morphology required for bacterial and fungal cell growth. 

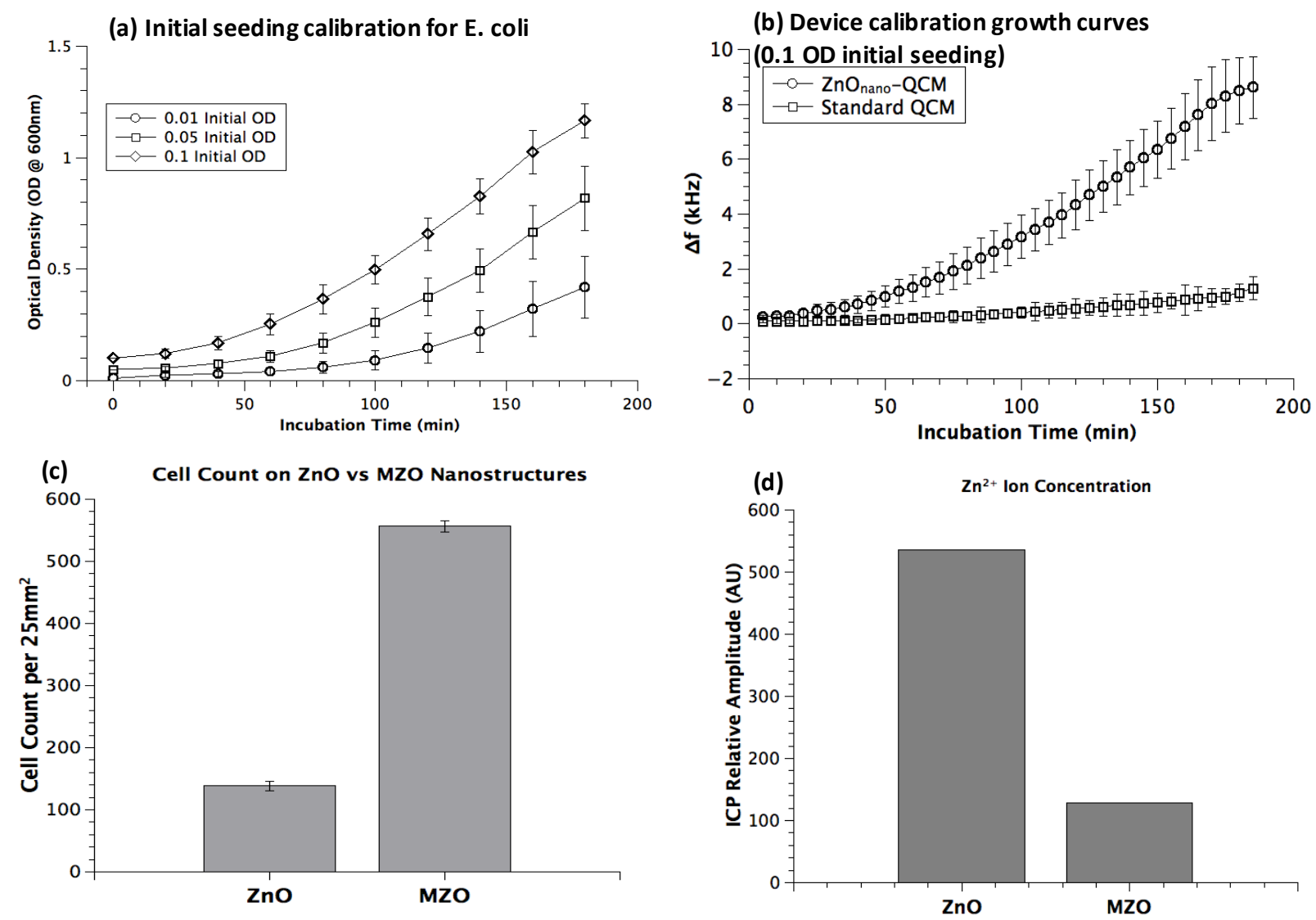

Fig. 2. (a) $\mathrm{OD}_{600}$ growth curves for various initial seeding concentrations of $E$. coli showing $\mathrm{OD}_{600}=0.1$ as the optimal initial cell seeding concentration for the experimental setup, and (b) biosensor time dependent frequency shift plot with devices initially seeded with $\mathrm{OD}_{600}=0.1 \mathrm{E}$. coli cells. The biosensors show good agreement with the optimal calibration curve. (c) Comparison of cell counts of E. coli cells growing on $\mathrm{ZnO}$ and MZO films showing 4 times more cells in MZO than in $\mathrm{ZnO}$ films, (d) ICP-MS results showing 4 times less $\mathrm{Zn}^{2+}$ ion concentration in cell medium containing MZO compared to $\mathrm{ZnO}$. 

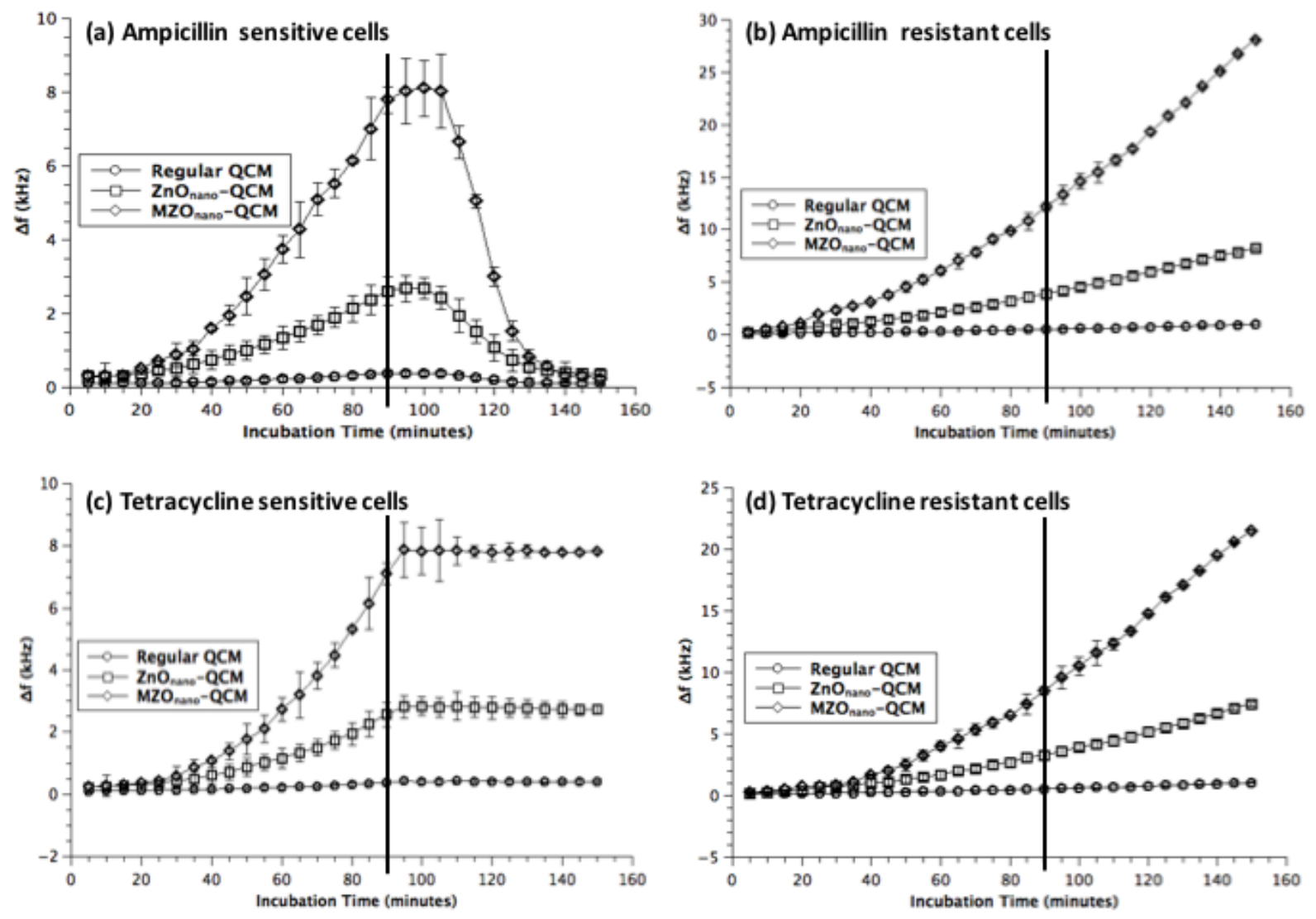

Fig. 3. Time dependent frequency shift plots of the $\mathrm{MZO}_{\text {nano }}-\mathrm{QCM}, \mathrm{ZnO}_{\text {nano }}-\mathrm{QCM}$ and regular $\mathrm{QCM}$ show detection of (a) effects of ampicillin on drug sensitive strain of E. coli, (b) effects of ampicillin on drug resistant strain of E. coli, (c) effects of tetracycline on drug sensitive strain of E. coli, and (d) effects of tetracycline on drug resistant strain of $E$. coli. The vertical lines at 90 minutes represent the time point when the drugs (ampicillin and tetracycline) were introduced into the cell culture. 

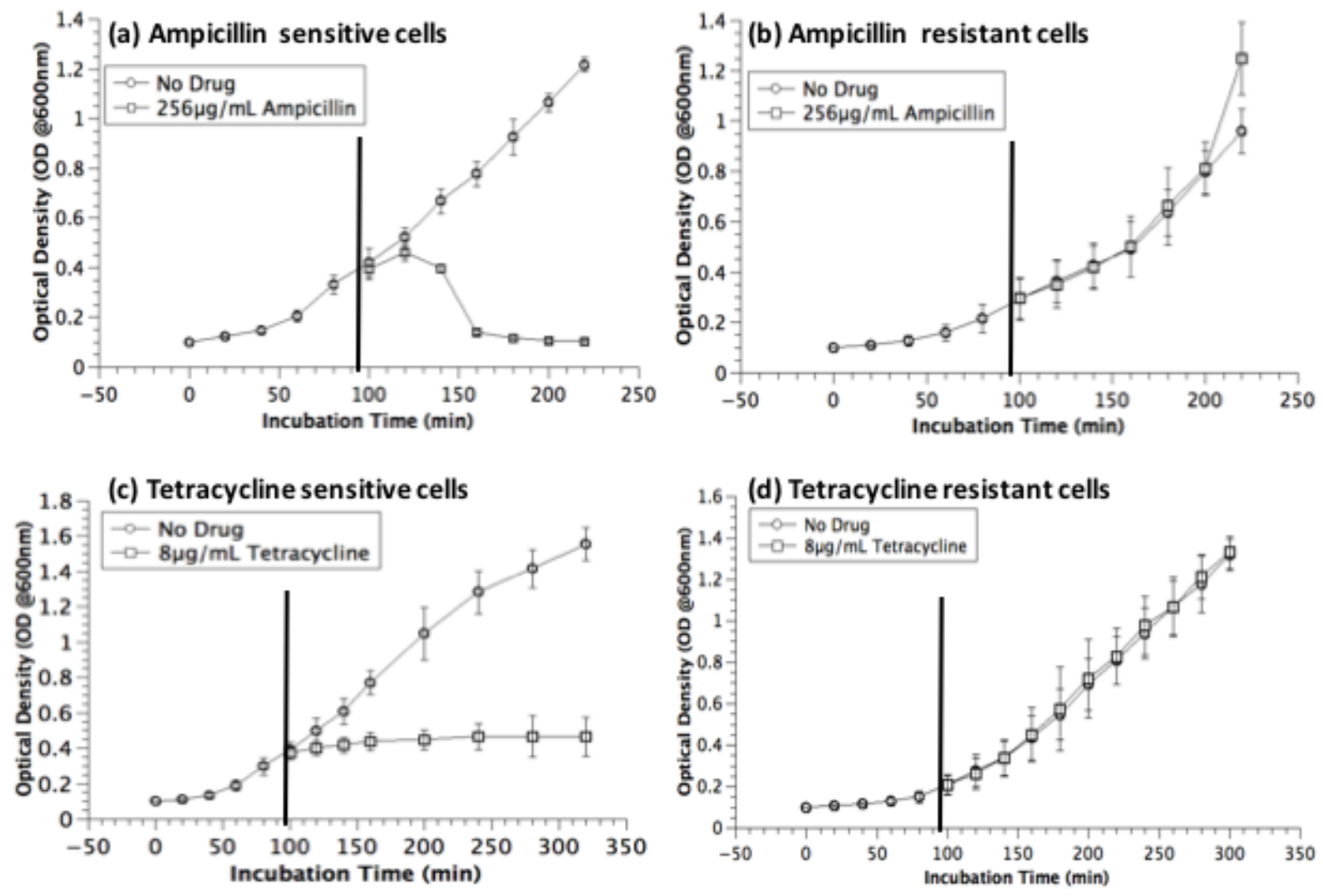

Fig. 4. Time dependent $\mathrm{OD}_{600}$ plots showing detection of (a) effects of ampicillin on drug sensitive strain of $E$. coli, (b) effects of ampicillin on drug resistant strain of E. coli, (c) effects of tetracycline on drug sensitive strain of E. coli, and (d) effects of tetracycline on drug resistant strain of E. coli. The $\mathrm{OD}_{600}$ measurements verify the trends exhibited by the biosensor outputs. The vertical lines at 90 minutes represent the time point when the drugs (ampicillin and tetracycline) were introduced into the cell culture. 

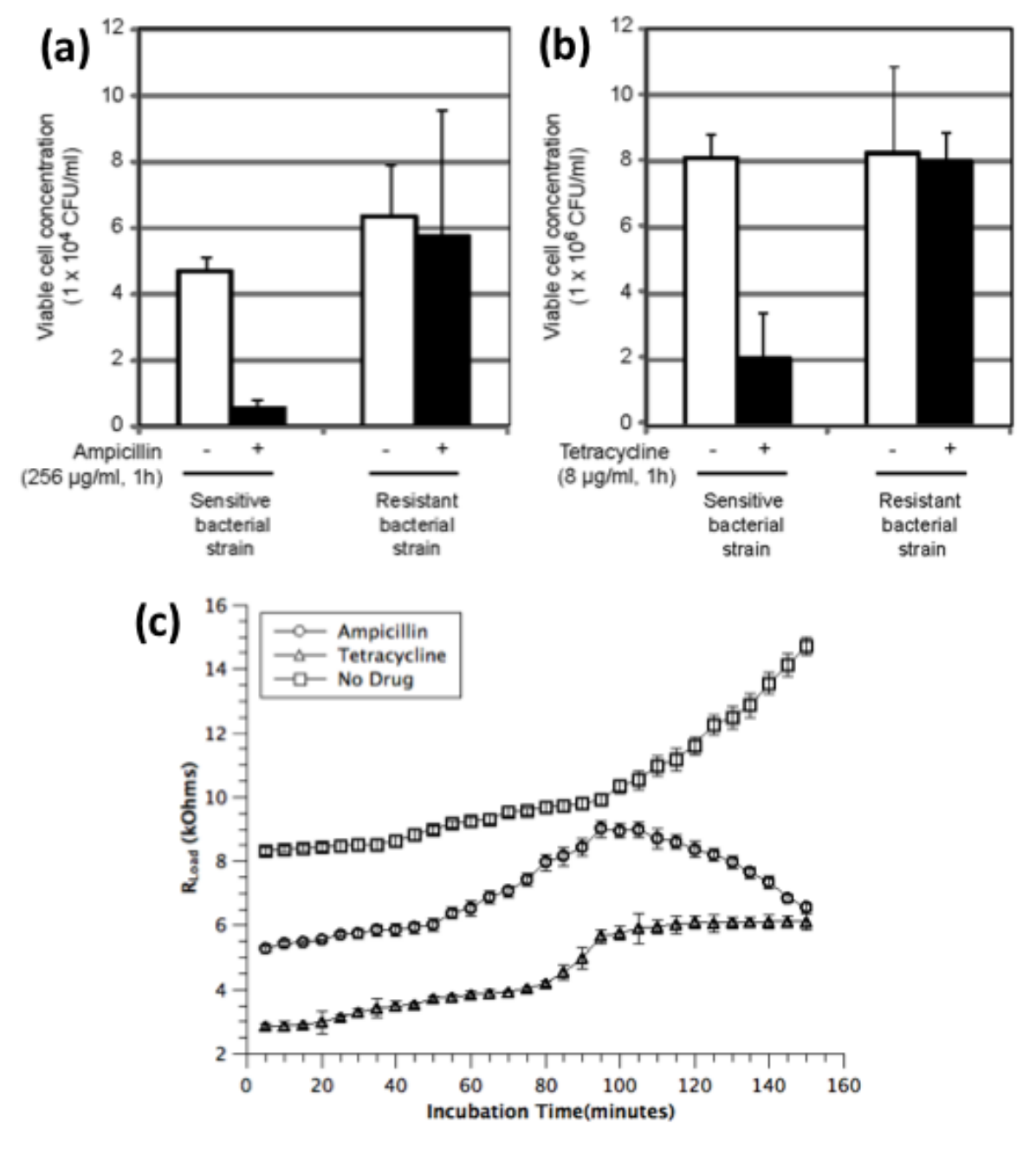

Fig. 5. (a) Viability assay histogram of the ampicillin effects on sensitive and resistant strains of E. coli, (b) Viability assay histogram of the tetracycline effects on sensitive and resistant strains of E. coli, (c) Motional resistance $\mathrm{R}_{\mathrm{Load}}$ calculated from the sensors' admittance spectrum amplitude modulation for cases with ampicillin treatment (circles), tetracycline treatment (triangles) and no drug treatment (squares). The graphs were shifted vertically by $2 \mathrm{kOhm}$ apart to show the details. 

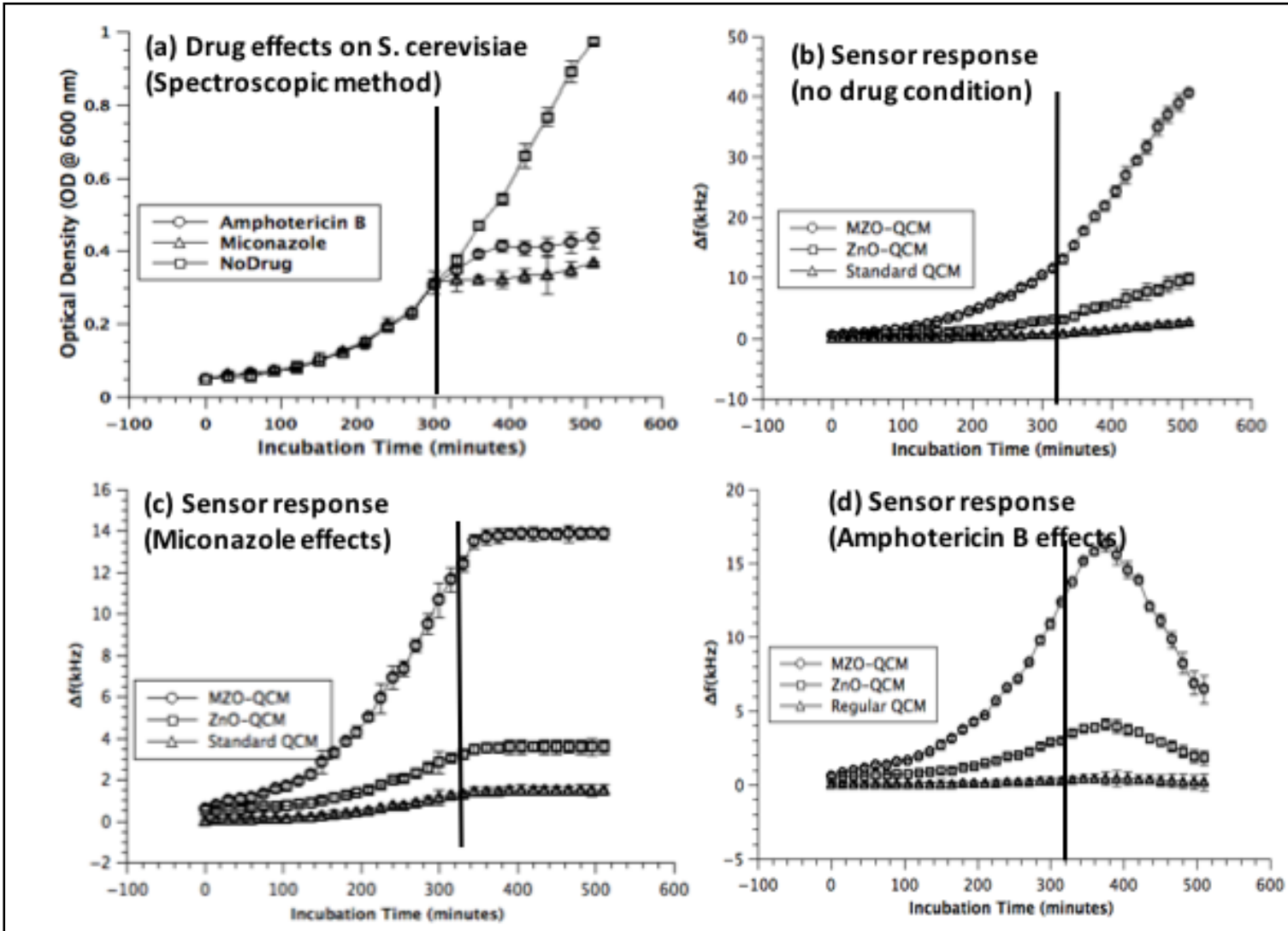

Fig. 6. (a) $\mathrm{OD}_{600}$ measurements of the effects of amphotericin $\mathrm{B}$ and miconazole on S. cerevisiae, (b-d) results of the dynamic biosensor response measurements using $\mathrm{MZO}_{\text {nano }}-\mathrm{QCM}$ (black graph) and $\mathrm{ZnO}_{\text {nano }}-\mathrm{QCM}$ (red graph) to monitor the effects of amphotericin B and miconazole on S. cerevisiae. The $\mathrm{OD}_{600}$ method could not distinguish between amphotericin B and miconazole effects while the biosensor devices accurately detected the difference. The vertical lines at 330 minutes represent the time point when the drugs (amphotericin B and miconazole) were introduced into the yeast culture. 


\section{References}

Alessandrini, A., Croce, M.A., Tiozzo, R., Facci, P., 2006. Appl. Phys. Lett. 88, 083905.

Lord, M.S., Modin, C., Foss, M., Duch, M., Simmons, A., Pedersen, F.S., Milthorpe, B.K.,

Besenbacher, F., 2006. Biomaterials, 27, pp. 4529-4537.

Blount, Z., 2015., eLife 4, e05826, DOI: http://dx.doi.org/10.7554/eLife.05826.

Botstein, D., Fink, G., 2011. Yeast: An Experimental Organism for 21st Century Biology, Genetics. 189, 3, pp. 695-704.

Braunhut, S. J., McIntosh, D., Vorotnikova, E., Zhou, T., Marx, K.A., 2005. Assay and Drug Dev. Technol., 3, 1, pp. 77-88.

Brenner, T.M., Flores, T.A., Ndione, P.F., Meinig, E.P., Chen, G., Olson, D.C., Furtak, T.E., Collins, R.T., 2014. J. Phys. Chem C, 118, pp. 12599-12607.

Brown, G.E., Henrich, V.E., Casey, W.H., Clack, D.L., Eggleston, C., Felmy, A., Goodman, D.W., Gratzel, M., Maciel, G., McCarthy, M.I., Nealson, K.H., Sverjensky, D.A., Toney, M.F., Zachara, J.M., 1999. Chem. Rev. 99, pp. 77-174

Center for Disease Control and Prevention, U.S. Department of Health and Human Services, 2013. Antibiotic Resistance Threats in the United States, pp. 11-12. 
Christianson, T.W., Sikorski, R.S., Dante M., Shero, J.H., Hieter, P., 1992. Gene, 110, 1, pp. $119-122$.

Chabot, V., Cuerrier, C., Escher, E., AImez, V., Grandois, Charette, P., 2009. Biosens Bioelectron J., 24, pp. 1667-1673.

Chen, Y., Saraf, G., Lu, Y., Wielunski, L.S., Siegrist, T., 2007. J. Vac. Sci. Technol A, 25, 4, pp. 857.

Domingues, M.C., de la Rosa, M., Victoria Borobio, M., 2001. J. Antimicrob. Chemother., 47, pp. 391-398.

Emanetoglu, N.W., Muthukumar, S., Wu, P., Wittstruck, R., Chen, Y., Lu, Y., 2003. IEEE Trans. Ultrason, Ferroelec. Freq. Control, 50, 5, 537.

Della Ventura, B., Funari, R., Anoop, K. K., Amoruso, S., Ausanio, G., Gesuele, F., Velotta, R., Altucci, C., Appl. Phys. B (2015) 119: 497.

Giebel K.F., Bechinger C., Herminghaus S., Riedel M, Leiderer P., et al. 1999. Biophys. J. 76, pp. 509-16.

Heiland, G., Kunstmann, P., 1969. Surf. Sci. 13, pp. 72- 84. 
Hupkes, J., Owen, J.I., Pust, S.E., Bunte, E., 2012. Chem. Phys. Chem. 13, pp. 66 - 73.

Jorgensen, J,, Turnidge, J., 2015. Susceptibility Test Methods: Dilution and Disk Diffusion Methods, in: Jorgensen J., Pfaller M., Carroll K., Funke G., Landry M., Richter S., Warnock D. (Eds.), Manual of Clinical Microbiology, Eleventh Edition. ASM Press, Washington, DC. doi: 10.1128/9781555817381.ch71, pp. 1253-1273.

Ku, C.J., Duan Z., Reyes, P.I., Lu, Y., Xu, Y., Hsueh, C.L., Garfunkel E., 2011. Appl Phys Lett. 98, 12, pp. 123511.

Li, H., Tsang, C.K., Watkins, M., Bertram, P.G., Zheng, X.F.S., 2006. Nature 442, 7106, pp. $1058-1061$.

Livermore, D., Blaser, M., Carrs, O., Cassell, G., Fishman, N., R. Guidos, R., Levy, S., Powers, J., Norrby, R., Tillotson, G., Davies, R., Projan, S., Dawson, M., Monnet, D., Keogh-Brown, M., Hand, K., Garner, S., Findlay, D., Morel, C., Wise, R., Bax, R., Burke, F., Chopra, I., Czaplewski, L., Finch, R., Livermore, D., Piddock L., White, T., 2011. J. Antimicrob. Chemother. 66, 9, 1941-1944.

Nel, A.E., Madler, L., Velegol, D., Xia, T., Hoek, E.M.V., Somasundaran, P., Klaessig, P., Castranova, V., Thompson, M., 2009. Nature Materials, 8, pp. 543.

Odonkor, S., Addo, K., 2015. Int. J. Biol. Med. Res. 2, 4, 1204 - 1210. 
Pourbaix, M., Atlas of Electrochemical Equilibria in Aqueous Solutions, National Association of Corrosion Engineers, Houston, 1974, p. 411.

Reyes, P.I., Ku, C.J., Duan, Z., Lu, Y., Solanki, A., Lee, K.B., 2011. Appl. Phys. Lett. 98, 17, 173702.

Reyes P.I., Duan Z., Lu Y., Khavulya D., Boustany N., 2013. Biosens Bioelectron., 15, 41 pp. 84-89.

Syal, K., Iriya, R., Yang, Y., Yu, H., Wang, S., Haydel, S. E., Chen, H. Y., and Tao, N., ACS Nano, 2016, 10 (1), pp 845-852.

G. Sauerbrey, Z. Phys 155, 206 (1959).

Taratula, O., Galoppini, E., Wang, D., Chu, D., Zhang, Z., Chen, H., Saraf, G., Lu, Y., 2006. J. Phy. Chem. B, 110, 13, pp. 6506-6515.

Tsang, C.K., Zheng, X.F.S., 2009. J. Biol. Chem., 284, pp. 21908-21919.

World Health Organization (WHO), 2014. Antimicrobial resistance: global report on surveillance, pp. 10-11. 
Yourassowsky, E., Van der Linden, M. P., Lismont, M. J., Crokaert, F., \& Glupczynski, Y. 1985. Antimicrob Agents Chemother., 28, 6, pp. 756-760.

Zhang, Z., Emanetoglu, N. W., Saraf, G., Chen, Y., Wu, P., Zhong, J., Lu, Y., Chen, J., Mirochnitchenko, O., Inouye, M., 2006. IEEE Trans. Ultrason. Ferroelect. Freq. Control, 53, 4, pp. 786-792.

Zhang, Z., Chen, H., Zhong, J., Saraf, G., Lu, Y., 2007. J. Electron. Mater. 36, 8, pp. 895-899.

Wegener, J., Seebach, J., Janshoff, A. ,Galla, H.-J., 2000. Biophysical J. 78, pp. 2821-2833. 